\title{
Developments in silicone technology for use in stoma care
}

Thomas Swift, University of Bradford; Gillian Westgate, University of Bradford; Julie Van Onselen, Dermatology Education Partnership; Stewart Lee, Trio Healthcare

t.swift@bradford.ac.uk

\begin{abstract}
Soft silicone's flexibility, adhesive capacity and non-toxic, non-odourous and hypoallergenic nature have made it an established material for adhesive and protective therapeutic devices. In wound care, silicone is a component of contact layer dressings for superficial wounds and silicone gel sheeting for reducing the risk of scarring, as well as of barriers for incontinence-associated dermatitis. Regarding stoma accessories, silicone is established in barrier films to prevent contact dermatitis, adhesive removers to prevent skin stripping and filler gels to prevent appliance leaks. Until recently, silicone has not been used in stoma appliances flanges, as its hydrophobic nature has not allowed for moisture management to permit trans-epidermal water loss and prevent maceration. Traditional hydrocolloid appliances manage moisture by absorbing water, but this can lead to saturation and moisture-associated skin damage (MASD), as well as increased adhesion and resultant skin tears on removal, known as medical adhesive-related skin injury (MARSI). However, novel silicone compounds have been developed with a distinct evaporation-based mechanism of moisture management. This uses colloidal separation to allow the passage of water vapour at a rate equivalent to normal trans-epidermal water loss. It has been shown to minimise MASD, increase wear time and permit atraumatic removal without the use of adhesive solvents. Trio Healthcare has introduced this technology with a range of siliconebased flange extenders and is working with the University of Bradford Centre for Skin Sciences on prototype silicone-based stoma appliance flanges designed to significantly reduce the incidence of peristomal skin complications, such as MARSI and MASD. It is hoped that this will also increase appliance wear time, reduce costs and improve patient quality of life.
\end{abstract}

Keywords

- Medical adhesive-related skin injury

- Moisture management

- Moisture-associated skin damage

- Silicone

- Transepidermal water loss

\section{Introduction}

Silicone describes any long-chain inert polymer that contains repeating chains of the element silicon, along with oxygen, carbon and hydrogen. There are a variety of silicone compounds used for various industrial purposes, but this article will focus on the type of soft silicone used in therapeutic medical devices. It charts the development of this technology and reviews the evidence for its efficacy compared with more traditional materials, beginning with silicone's 
established use in dermatology, wound care and stoma accessories. This is followed by an acknowledgement of the challenges presented by moisture management that have limited silicone's application in flanges for stoma appliances. The article then introduces new silicone compounds that are able to overcome these limitations with a novel method moisture management, with considerable advantages over traditional hydrocolloid appliances.

Soft silicone polymers have a variety of advantages that make them particularly suitable for use. They are highly flexible, which allows them to conform well to the shapes and contours of the body. They have a tacky quality that allows them to adhere to dry surfaces and a low surface energy that provides instant adhesion. They are non-toxic, non-odorous and have a low allergy potential, as well as being impermeable to bacteria and incapable of being absorbed into the body, all of which makes them comfortable and hygienic to wear (Meuleneire and Rücknagel, 2013; Cronin, 2016).

\section{Silicone in wound and continence care}

Up to the beginning of the 21st century, wound dressings and similar devices designed to provide moisture and protect the surrounding skin were primarily made from hydrocolloids and hydrogels, as well as alginates (Ghomi et al, 2019). The early 2000s saw the introduction of silicone-based wound dressings, which have successfully applied the advantages outlined above to protecting periwound skin and minimising pain and trauma at dressing change (Meuleneire and Rücknagel, 2013).

\section{Silicone wound contact layer dressings in superficial wounds}

Silicone's atraumatic properties make it an ideal material for wound contact layer (WCL) dressings - dressings applied directly to a wound to protect it from direct contact with harmful substances and ensure an appropriately moist environment to promote healing. Because silicone adheres to the periwound skin but not to the wound bed, removing a WCL dressing made of silicone, compared with other materials, is less likely to result in skin tears, which can cause pain and further damage to the wound (White, 2014). This makes these dressings effective at protecting both the periwound skin and the wound bed, and they are especially appropriate in superficial wounds where skin is vulnerable, such as skin tears, burns, incontinence-associated dermatitis (IAD) and blistering diseases, where skin is vulnerable (Meuleneire and Rücknagel, 2013).

Silicone-based dressings have a number of clinical advantages over older, non-silicone products. For example, silicone adhesives do not deteriorate and become tacky over time. This is in contrast to hydrocolloid adhesives, which, as they absorb moisture, can become difficult to remove without potentially damaging fragile skin (Chadwick 2014; Cronin, 2016). Hydrocolloids also do not absorb wound exudate effectively, resulting in maceration and/or excoriation of the wound (Chadwick, 2014; Cronin, 2016).

A number of studies have shown that WCLs incorporating soft silicone technology result in improved outcomes for patients with exuding or non-exuding wounds compared with older product materials (Patton et al, 2013; Matsumura et al, 2014; Bateman, 2015; Suess-Burghart et al, 2015; David et al, 2018). A study by Klode et al (2011) evaluated the adhesive areas of 56 wound dressings (acrylate, $n=23$; silicone, $n=9$; hydrocolloid, $n=17$ and polyurethane, $n=7$ ) in healthy human volunteers by measuring the peel force required to remove the dressing 
from skin and the subjective pain intensity during removal using a visual analogue scale. The results showed statistically significant correlation between the adhesion and pain intensity, with the lowest pain intensity for silicone dressings. An observational study by Bateman (2015) examined 150 patients with acute or chronic exuding wounds treated using a foam dressing containing soft silicone. After 4 months, the data showed improvements in adherence, exudate management, maceration reduction and atraumatic application and removal.

There are a variety of silicone-based dressings-including bi-stretch soft silicone, soft silicone mesh, soft silicone fixation tape, soft silicone foam and soft silicone foam with superabsorbers - that have been used successfully in the treatment of blistering diseases, such as epidermolysis bullosa (EB). EB is a group of rare, inherited skin disorders characterised by fragility and blistering of skin and mucous membranes, from even minimal friction or trauma. Patients with EB are vulnerable to a number of complex, chronic problems, including pain from blisters, skin erosion and skin scarring, which can involve the hands, feet, mouth, eyes and oesophagus. Children with EB can also experience secondary complications, including failure to thrive, nutritional deficiencies, cancer and anaemia (Danial et al, 2015). This makes wound care a particular challenge for the parents of these children. Recent clinical guidelines (Denyer et al, 2017) describe the underlying principle of lesion management in EB as the application of an atraumatic dressing to prevent blistering and damage to skin and wound bed, which can lead to pain and bleeding on removal. Dressings must be removed carefully to avoid further skin damage, and the use of a silicone medical adhesive remover (SMAR) can be helpful (Denyer et al, 2017). These principles also apply to other blistering conditions, such as bullous pemphigus, bullous pemphigoid and Hailey-Hailey disease.

\section{Silicone gel sheeting in wounds at risk of scarring}

Silicone has been used for some time in the treatment of healed wounds to reduce or prevent hypertrophic and keloid scarring (Meuleneire and Rücknagel, 2013). Hypertrophic scars are red and raised above the surface, but do not go beyond the boundaries of the original wound site; they can continue to thicken for up to 6 months and can be very itchy or painful (Van Onselen, 2019). Keloid scars, by contrast, grow beyond the boundary of the original wound site due to an overproduction of collagen; they can develop up to 1 year after injury and are painful, itchy and unsightly (Van Onselen, 2019).

Silicone gels and silicone gel sheeting (SGS) are both used to help reduce scarring, and there is no evidence to suggest that one is more effective than the other (Lin et al, 2018). Although the mechanism of action is not known, it is believed to relate to wound hydration. There is evidence that SGS affects the hydration status of the scar by decreasing the water vapour evaporation rate to almost half that of normal skin, causing a build-up of moisture on the skin surface under the SGS (Gilman, 2003). This increased hydration seems to be responsible for reduced capillary activity, hyperaemia and collagen deposition (Niessen et al, 1998), as well as causing electrostatic changes that influence collagen deposition and remodelling within the scar (Hirshowitz et al, 1993).

A reduced water evaporation rate that results in accumulation of water below the SGS can lead to skin maceration (Chan et al, 2005), other common side-effects associated with SGS include pruritus, skin breakdown, skin rash, and there are reported issues with poor durability 
of the sheet, failure of the sheet to improve the hydration of dry scars and poor patient compliance (Rabello et al 2014).

A review by Hoeksema et al (2013) compared several types of semi-occlusive silicone products for scar reversal using trans-epidermal water loss (TEWL) and stratum corneum moisture levels as measured endpoints. The study suggested that products that reduce TEWL to near normal values help skin recover, and this could be of value when considering the relative occlusive properties of new silicone adhesive formulations in development.

A Cochrane review and an update of clinical guidelines regarding the prevention and treatment of scars (O'Brien and Jones, 2013; Meaume et al, 2014) both highlighted silicone-based products, including sheets and gels, as improving scar thickness and scar colour. Such products have been suggested by a European Working Group as first line prophylactic and non-invasive treatment options for all scars (Gold et al, 2014; Monstrey et al, 2014; Van Onselen, 2019).

\section{Silicone barriers in incontinence-associated dermatitis}

The complications of incontinence-whether of urine, faecal matter or both-include incontinence-associated dermatitis (IAD) (Langemo et al, 2011). IAD occurs when chronic or repeated exposure to urine or faecal matter leads to the breakdown and inflammation of the perineal skin, potentially involving maceration, blistering and/or loss of the skin barrier function (Beeckman et al, 2017).

Management of IAD, according to a 2016 Cochrane review, should focus on skin cleansing to remove dirt, debris and microorganisms; skin moisturisation to repair or enhance the skin's barrier; and the application of skin protectants (Beeckman, 2017). The Cochrane review states that, in practice, products and procedures are the same for both prevention and treatment, and the aim should be to protect the skin from further exposure to irritants.

Silicone-based barrier products, such as dimethicone, have been used in the prevention and treatment of IAD. These spread easily and are conformable to the periwound area or area of at-risk skin (Woo et al, 2017). In an alternative approach, Beeckman et al (2011) compared the effectiveness of a three-in-one, pre-moistened, perineal washcloth impregnated with $3 \%$ dimethicone vs standard of care in the prevention and treatment of IAD in 141 nursing home residents. After 4 months, there was a reduction in the prevalence of IAD in those treated with the $3 \%$ dimethicone washcloth (8.1\% vs $27.1 \%$ ) (Beeckman et al, 2011).

\section{Silicone in stoma accessories}

The skin surrounding a stoma, known as peristomal skin, is vulnerable to a number of complications that can cause considerable physical discomfort and emotional distress (Figure 1) (Keeling, 2015). Different studies have reported the incidence of peristomal skin complications to be between $35 \%$ and $74 \%$, and those with an ileostomy are at the greatest risk (Herlufson et al, 2006; Richbourg, 2007; Williams et al, 2010; Salvadalena, 2013).

Although common, these complications can generally be prevented or resolved with correct use of the most appropriate stoma appliance (also known as a bag or pouch) and stoma care accessories for the patient's particular needs. A number of silicone-based stoma care accessories have been developed that have been shown to be effective at addressing these 
complications, including barrier films, adhesive removers and fillers (Cronin, 2016). Silicone is non-toxic non-alcohol based, and thus non-irritant, as well as able to repel water and chemical attack, all of which help these accessories maintain skin integrity, appliance adherence and patient comfort (White, 2014).

\section{Silicone barrier films to prevent contact dermatitis}

The most common peristomal skin complication is contact dermatitis. Contact dermatitis manifests as irritation and redness, and it occurs when the skin is exposed to the stoma's corrosive effluent (faeces or urine), typically after a gap forms in the seal between skin and appliance flange (also known as a wafer, faceplate or baseplate) (Burch, 2020).

Barrier films are accessories that provide a temporary layer of protection against contact with harmful substances, as well as improving appliance adhesion (Figure 2). Available as wipes or sprays, barrier films are applied directly to the peristomal skin before the appliance is fitted. Silicone-based barrier films are long-lasting and pain-free, and patented formulations have been developed that serve to protect the stratum corneum from chemical irritants and soothe reddened and sore skin. Newer barrier films contain cyanoacrylate, as well as silicone.

Barrier films are used wherever there is likely to be contact with an irritant, and they are an established treatment for extant contact dermatitis. There is debate as to whether they should also be used as a preventative measure in healthy peristomal skin. This is an extra cost burden, but some stoma care nurses do encourage its use after hospital discharge (Rudoni and Dennis, 2009). Prevention is often better than cure, because, once peristomal skin becomes damaged, it is harder to control leakage and prevent further harm, and, once usage is stopped, the skin may again be exposed to damage.

\section{Silicone adhesive removers to prevent skin stripping}

As with wound dressings, the adhesive flange, which keeps appliance on the skin and forms a seal around the stoma, needs to be removed. Repeated and/or traumatic removal can lead to painful skin stripping. As a conservative measure, patients can be encouraged to be gentler in how they remove their appliances. Likewise, although stoma appliances need to be changed on a regular basis, ostomates should be encouraged to minimise removals by maximising the wear time of their flange, perhaps by switching to a two-piece appliance.

This advice may not be sufficient for all ostomates, especially those with delicate skin. These patients may benefit from using adhesive removers, available as sprays and wipes, which loosen the adhesive bond to make removal easier and less likely to damage the skin. These were traditionally based on either alcohol or oil. However, these have been superseded by silicone-based adhesive removers (Figure 3), which have the advantages of evaporating quickly and avoiding skin dryness, stinging sensation and persistent sticky residue associated with traditional alcohol- and oil-based solvents (Burch, 2011). Any adhesive residue left by an appliance change should be removed to prevent the skin from drying, which leaves it susceptible to breakdown. More recent silicone formulations have been improved to eliminate environmentally harmful cyclic siloxanes. 


\section{Silicone fillers to prevent stoma appliance leaks}

As well as causing contact dermatitis, gaps in the seal between appliance and peristomal skin can further weaken the appliance adhesion, often resulting in leakage of effluent that causes odour, soiling and serious negative psychosocial consequences. Although leaks are a common problem for many ostomates, they can usually be significantly minimised with appropriate accessories (White, 2014).

Flanges adhere best to flat peristomal skin around a spouted stoma. Leaks are made more likely by issues with the stoma itself, whether it is retracted, prolapsed or poorly sited, as well as by an uneven skin surface. Many peoples' abdomen contains dips, creases and folds, and these can develop with age, changes in weight and other complications, such as a parastomal hernia. A number of silicone-based stoma accessories have been developed to compensate for these issues.

Fillers, available as pastes and gels (Figure 4), are squeezed from a tube or syringe into recesses in the skin, where they are sculpted into a flat surface for the flange to adhere to. Older filler pastes took some time to set before the flange could be applied. However, siliconebased filler gels set in just 20 minutes of application via a process known as room-temperature vulcanisation, triggered by the moisture and humidity that emanates from the skin surface (White et al, 2014; Cronin, 2016). Silicone gels are also waterproof, transparent and tacky to the touch.

\section{Challenges of moisture management}

Until recently, despite silicone's established success in many stoma accessories, it has not been applicable to the important piece of ostomy equipment, the appliance flange itself. This is because the same hydrophobic and occlusive properties that make silicone so effective as a protective material also traditionally present challenges for devices that require an effective system of moisture management. An understanding of these limitations, and how they can be overcome requires an explanation of how silicone interacts with the outermost layer of the skin, the stratum corneum.

\section{The stratum corneum and trans-epidermal water loss}

The stratum corneum (Figure 5) is around 10-20 $\mu \mathrm{m}$ thick and is composed of enucleated and flattened corneocytes, formed from terminal differentiation of epidermal keratinocytes. Corneocytes are interleaved with many lamellae sheets enriched with cell-bound free fatty acids and ceramides (Matsui et al, 2015). Among the most crucial of the stratum corneum's many protective functions is as a permeability barrier that ensures the body remains watertight and permits survival in very dry environments. There is a steady flux of water through the skin, as it diffuses from the extremely hydrated lower layers of the epidermis and dermis to the stratum corneum, before exiting the skin via either the sweat glands or TEWL (Machado et al, 2010).

The rate of flux varies, with higher TEWL associated with smaller corneocytes, warmer tissue temperature and lower air humidity (boundary layer water vapour pressure), as well as thinner parts of the stratum corneum and bodily extremities, such as the feet and palms. Higher TWEL is also linked to disrupted (irritated or mechanically damaged) skin, and a slower rate of 
diffusion is usually linked to a healthier permeability barrier (Taylor et al, 2013). TEWL can be tested with simple and inexpensive equipment, such as a handheld vapour meter, which gives results in $\mathrm{g}^{-2} \mathrm{hr}^{-1}$. This test should ideally occur under standardised environmental temperature and humidity, and after a period of acclimatisation following removal of clothing or any other covering that may affect boundary-layer water vapour pressure.

\section{Moisture-associated skin damage}

Many protective devices are designed to cover the skin or wound bed to protect it from harmful contact with external substances. However, an occlusive device with low water permeability can also obstruct the normal evaporation of water from the skin, leaving it to build up in the stratum corneum, which has a significant absorptive capacity (300-400\% of its dry weight) (Gray et al, 2011). In healthy skin, when occlusion is removed, the accumulated water will evaporate at a higher rate than normal until a healthy equilibrium is restored, meaning that even repeated short-term occlusion should not have adverse effects (Gioia et al, 2002). However, prolonged occlusion can lead to maceration, along with mild skin irritation, which can adversely affect barrier function and lead to moisture-associated skin damage (MASD) (Bowstra et al, 2003; Warner et al, 2003; Jungersted et al, 2010; Whitehead et al, 2017). Even short-term occlusion can be problematic in scar tissue, which has a raised TEWL, and in stretch marks at the affected site, which can have altered barrier properties (Dabboue et al, 2015).

Therefore, protective devices that need to be worn for long periods, or on skin with altered barrier function, require an effective system of moisture management to prevent maceration. The hydrophobic nature of silicone has traditionally made it unsuitable as a material for managing moisture. Instead, this has traditionally been achieved by using devices made of hydrocolloid, a highly absorptive material that draws moisture away from the skin. However, as moisture is absorbed, the device swells in volume, becomes deformed and increases in adhesive strength (Figure 6) (Ferrari et al, 1994; 1995). Eventually, the hydrocolloid becomes saturated, losing its ability to manage moisture and, instead, contributing to maceration and resulting in warm and humid conditions ideal for pathological micro-organism proliferation (Lyon, 1999). This degradation of function limits the effective wear time of hydrocolloid devices (Figure 7).

\section{Medical adhesive-related skin injury}

Many medical devices are held in place with an adhesive component that is attached to the patient's skin. This needs to be adhesive enough to stay in place, but not so adhesive that it cannot be removed without causing excoriation. Excoriation occurs when the bond between the device and the skin is stronger than the bond between the cells within the stratum corneum, so that, when the device is removed, skin cells in the topmost layer, including corneocytes, are pulled with it. This excoriation makes the process of removal painful for the patient and the skin more vulnerable to infection and disease. The more frequently adhesive devices are removed from a patch of skin, the greater the risk or severity of skin tearing, known as medical-adhesive related skin injury (MARSI) (Farris et al, 2015).

This is a problem for adhesive devices made from hydrocolloids. As hydrocolloid absorbs moisture, it becomes tacky and more adhesive, requiring a greater peel force to remove (Figure ${ }^{8}$ ). Thus, the longer a hydrocolloid device is worn, the more likely it is to be difficult to 
remove and result in discomfort, pain and/or MASD. These issues may be blamed on poor application technique or pre-existing conditions, when they result from chemical deficiencies inherent to the hydrocolloid material (Williams et al, 2010).

\section{Moisture management in novel silicone stoma flanges}

This risks of MARSI and MASD, and associated limited wear time, are significant drawbacks for hydrocolloid as a material for stoma appliance flanges. This has led to the development of novel silicone compounds that overcome the limitations of traditional silicone technologies to provide a novel method of moisture management that has significant clinical advantages over traditional hydrocolloid flanges.

\section{Mechanism of action}

Rather than absorbing water, silicone is water-repellent (hydrophobic), composed of fully crosslinked inorganic polymer chains (Owen, 2014). However, a compound of silicone and water-attracting (hydrophilic) additives has a natural microporosity that, when cast in sheets or wafers, allows water to pass through it as vapour, while still repelling aqueous liquids. As this moisture is not permanently retained, silicone devices do not undergo the marked swelling, increased adhesion, saturation and degradation of function associated with hydrocolloids.

This works via colloidal separation, in which water molecules can osmose through a sea of hydrophobic silicone particles (the oily phase) by diffusing between microscopic islands of hydrophilic polymers (the aqueous phase). This is a key advantage, as traditional unmodified silicone dressings were either restricted to net materials with plenty of room for moisture penetration (Platt et al, 1996) or risked a reservoir of water building up beneath the dressing that could lead to patient complications (Nikkonen et al, 2001).

If formulated correctly, the silicone compound contains internal pores large enough for moisture vapour to diffuse (Figure 9). Hydrophilic additives play a crucial role in driving this phase separation. Materials using too strongly water-binding additives in too large a volume will result in the product retaining moisture and reduce TEWL at increased humidity (Lei et al, 2011). Absence of additive results in a completely water repellent material with almost no TEWL capacity at all. Composite materials can be designed with the most appropriate ratio of additives, as well as material thickness, to suit applications specific to temperature and humidity (Wang et al, 2017).

These novel silicone compounds are not only effective at reducing MASD, their non-absorptive method of moisture management also avoids the increased adhesion and risk of MARSI associated with hydrocolloids. The number of cells that remain stuck to the adhesive film can be used to measure the extent of skin damage (Gao et al, 2013), and MARSI has been shown to occur when adhesives have a peel force above 2N (Omura, 2010). The University of Bradford Centre for Skin Sciences ran an ex vivo study on behalf of Trio Healthcare to compare the peel force required to remove two otherwise equivalent prototype adhesive wafers, one made of silicone and the other of hydrocolloid. The wafers were attached to porcine skin, incubated in protein stain Ponceau $S$ and then rinsed in deionised water. The silicone wafers showed no protein removal (although there was background staining of the material, from white to a slight pink), while the hydrocolloids showed clear indications of protein 
stripping (evident from deep red particulate stains on the stripped adhesive material) (Figure 10). The peel force of the prototype silicone wafer was concluded to be sufficient to ensure adhesive stability but lower than that of hydrocolloid equivalents, with less potential for MASD. This appeared to result from increased TEWL and reduced osmotic swelling.

\section{Silicone flange extenders and ostomy seals}

For the past two decades, the adhesive flanges of stoma appliances have almost all been made from hydrocolloid, often with a polyurethane backing (Berry et al, 2007). Hydrocolloid superseded acrylate as the principal material for flanges, as hydrocolloid's absorptive mechanism of moisture management comparatively reduced the degree of maceration (Black, 2013), as well as reducing the potential for allergic reactions and providing potential cost savings (Smith et al, 2007). It is hoped that the material properties of the novel silicone compounds will again transform how stoma appliances manage moisture.

To explore the potential of these protype silicone compounds, Trio Healthcare launched a range of silicone accessories, including flange extenders (Figure 11) and ostomy seals (Figure 12). Flange extenders are accessories in the shape of strips and rings that extend the adhesive area of the stoma appliance flange, allowing for greater adhesion to uneven or otherwise problematic peristomal skin. An ostomy seal is a small ring that is moulded around the stoma to help prevent effluent from making contact with the peristomal skin in patients who have difficulty creating a perfect seal with an appliance flange alone. These accessories have similar material requirements for adhesion and protection to the flange itself, but are a more temporary, supportive measure. Compared with traditional hydrocolloid accessories, these silicone versions have benefit from the novel compound's non-absorptive mechanism of moisture management, which prevents maceration and excoriation, improves comfort and extends wear time. The silicone seal naturally settles back to its original shape and therefore provides a close fit around the contours of the stoma, moving with peristaltic motion of the bowel and ensuring a close contact at all times. This was a bridging step intended to provide the user experience necessary to develop the first appliances with flanges made from a silicone compound.

\section{Prototype silicone flanges for stoma appliances}

All this has led to the development of the first prototype stoma appliances with silicone-based flanges. The intention has been to create an appliance that is ideal for all types of peristomal skin-able to protect healthy skin, soothe irritated skin and encourage repair of damaged skin. This contrasts with hydrocolloid devices, which are not appropriate for use on excoriated skin (Berry et al, 2007). The challenge has been to engineer a reformulated silicone compound that is sufficiently microporous to permit optimal evaporation, while retaining silicone's protective properties and ensuring surface adhesion and long-term stability in use (Figure 13). Likewise, the chemical properties of the flange need to match the requirements of different kinds of skin, protecting and preserving its health and being gentle on inflamed skin during removal, and these chemical properties need to remain constant during use.

Prototype formulations from Trio Healthcare have been tested for TEWL at elevated humidity and temperature, as well as for peel force on removal from the stratum corneum, and these have so far shown promising results. Some choice in selection of a product with particular 
properties, depending on the status of the patient's skin, could be vital to ensure optimal healing and maintenance of skin health.

With a system of moisture management based on evaporation rather than absorption, silicone flanges appear to avoid maceration and excoriation of the stratum corneum, thus having the potential to significantly reduce the incidence of peristomal MASD and MARSI. This should improve not only peristomal skin health, but also ostomates' overall comfort, confidence and quality of life. These flanges should also extend the wear time of appliances and reduce the necessity of adhesive removers, reducing the major financial burden associated with stoma care.

\section{Conclusion}

In stoma care (as in dermatology, wounds and continence), promoting skin health is a high clinical priority, essential to the patient's physical and psychological wellbeing. Protective and adhesive technologies provide a number of indispensable tools for achieving healthy skin, but suboptimal application of these materials can have significant dermatological drawbacks. Therefore, understanding the considerable variation in available devices, including their indications and mechanism of action, is vital to make a sound evidence-based decision as to which is the most appropriate for a particular patient's needs (Meuleneire and Rücknagel, 2013).

The value of silicone wound and continence care and certain stoma accessories has been well established. However, the challenge of moisture management had previously held back silicone's full therapeutic potential from being applied to stoma appliance flanges and related accessories. This challenge has been met with the development of new silicone compounds that have a breathable matrix, which provides a more natural environment and allows the skin to stay healthy. This new material has a proven ability to effectively both adhere to and protect peristomal skin, without causing damage from maceration or excoriation. Compared with equivalent materials, its non-absorbent mechanism of moisture management prevents degradation and the increase of adhesion over time, thus maximising wear time and minimising traumatic removal (Cronin, 2016).

Declaration of interest: This article has been supported by Trio Healthcare

Acknowledgement: The authors would like to thank Dr Stephen Sikkink (University of Bradford, Centre for Skin Science) for carrying out Ponceau $S$ total protein staining

\section{References}

Bateman SD. 150 patient experiences with a soft silicone foam dressing. Br J Nurs. 2015;24(12 Suppl):S16-S23

Beeckman D, Van Damme N, Schoonhoven L et al, Interventions for preventing and treating incontinence-associated dermatitis in adults. Cochr Database Syst Rev. 2016; 11. Art. No.: CD011627. DOI: 10.1002/14651858.CD011627.pub2.

Beeckman D, Verhaeghe S, Defloor T, Schoonhoven L, Vanderwee K. A 3-in-1 perineal care washcloth impregnated with dimethicone $3 \%$ versus water and $\mathrm{pH}$ neutral soap to prevent and treat incontinence-associated dermatitis: a randomized, controlled clinical trial. J Wound Ostomy Continence Nurs. 2011;38(6):627-634 
Beeckman D. A decade of research on incontinence-associated dermatitis (IAD): evidence, knowledge gaps and next steps. J Tissue Viability. 2017;26(1):47-56

Berry J, Black P, Smith R, Stuchfield B. Assessing the value of silicone and hydrocolloid products in stoma care. Br J Nurs, 2007;16(13):778-788

Black P. The role of accessory products in patients with a stoma. Br J Nurs. 2013;22(5):S24.

Bock M, Damer K, Wulfhorst B, John SM. Semipermeable glove membrane-effects on skin barrier repair following SLS irritation. Contact Derm. 2009;61(5): 276-280.

Bouwstra JA, de Graaff A, Gooris GS, Nijsse J, Wiechers JW, van Aelst AC.et al. Water distribution and related morphology in human stratum corneum at different hydration levels. J Invest Dermatol. 2003;120(5):750-758

Buraczewska I, Broström U, Lodén M. Artificial reduction in trans-epidermal water loss improves skin barrier function. Br J Dermatol. 2007;157(1):82-86

Burch J. Peristomal skin care and the use of accessories to promote skin health. Br J Nursing. 2011;20(7 Suppl):S4-S10

Chadwick P. Current challenges in wound care. In: Novel technology for advanced wound dressings first clinical outcomes from an international multi-disciplinary perspective (conference report). Wounds Int. 2018;9(3):50-55

Chan KY, Lau CL, Adeeb SM, Somasundaram S, Nasir-Zahari M. A randomized, placebo-controlled, double-blind, prospective clinical trial of silicone gel in prevention of hypertrophic scar development in median sternotomy wound. Plast Reconstr Surg. 2005;116(4):1013-1020

Chekina NA, Pavlyuchenko VN, Danilichev VF, Ushakov NA, Novikov SA, Ivanchev SS. A new polymeric silicone hydrogel for medical applications: synthesis and properties. Polymers for Adv Tech. 2006;17(11-12):872-877

Cronin E. Silicone-based stoma accessories in clinical practice. Br J Nurs. 2016;25 (5 Suppl):S28-S34

Dabboue, H, Builles N, Frouin É, Scott D, Ramos J, Marti-Mestres G. Assessing the impact of mechanical damage on full-thickness porcine and human skin using an in vitro approach. Biomed Res Int. 2015;2015:434623 doi: 10.1155/2015/434623.

Danial C, Adeduntan R, Gorell EG. An evaluation of treatments for pruritus in epidermolysis bullosa. Pediatr Dermatol. 2015;32(5):628-634

David F, Wurtz JL, Breton $\mathrm{N}$ et al. A randomised, controlled non-inferiority trial comparing the performance of a soft silicone-coated wound contact layer (Mepitel One) with a lipidocolloid wound contact layer (UrgoTul) in the treatment of acute wounds. Int Wound J. 2018;1(1):159-169

Denyer J, Pillay E, Clapham J. Best practice guidelines for skin and wound care in epidermolysis bullosa. An International Consensus. Wounds Int. 2017;1-58

Farris MK, Petty M, Hamilton J, Walters SA, Flynn MA. Medical adhesive-related skin injury prevalence among adult acute care patients a single-center observational study. J Wound Ostomy Cont Nurs. 2015;42(6):589-598

Ferrari F, Bertoni M, Caramella C, Waring MJ. Comparative evaluation of hydrocolloid dressings by means of water uptake and swelling force measurements: I. Int J Pharm. 1994;112(1):29-36

Ferrari F, Bertoni M, Bonferoni MC, Rossi S, Caramella C, Waring MJ. Comparative evaluation of hydrocolloid dressings by means of water uptake and swelling force measurements: II. Int J Pharm. 1995;117(1):49-55 
Gao Y, Wang X, Chen S, Li S, Liu X. Acute skin barrier disruption with repeated tape stripping: an in vivo model for damaged skin barrier. Skin Res Technol. 2013;19(2):162-168

Ghomi ER, Khalili S, Khorasani SN et al. Wound dressings: current advances and future directions. Journal of Applied Polymer Science. 2019; 136(27):47738. https://doi.org/10.1002/app.47738

Gilman TH. Silicone sheet for treatment and prevention of hypertrophic scar: A new proposal for the mechanism of efficacy. Wound Rep Reg. 2003;11(3):235-236

Gioia F, Celleno L. The dynamics of trans-epidermal water loss (TEWL) from hydrated skin. Skin Res Technol. 2002;8(3):178-186

Gold MH, McGuire M, Mustoe TA et al. Updated international clinical recommendations on scar management: part 2 - algorithms for scar prevention and treatment. Dermatol Surg. 2014;40(8):825-831

Gray M, Black JM, Baharestani MM, et al. Moisture-associated skin damage: overview and pathophysiology. J Wound Ostomy Cont Nurs. 2011;38(3):233-241

Herlufsen $\mathrm{P}$, Olsen AG, Carlsen B et al. Study of peristomal skin disorders in patients with permanent stomas. Br J Nurs. 2006; 15(16):854-862. https://doi.org/10.12968/bjon.2006.15.16.21848

Hirshowitz B, Ullmann Y, Har-Shai Y, Vilenski A, Peled IJ. Silicone occlusive sheeting (SOS) in the management of hypertrophic scarring, including the possible mode of action of silicone, by static electricity. Eur J Plast Surg. 1993;16(1):5-9.

Jungersted JM, Høgh JK, Hellgren LI, Jemec GBE, Agner T. Skin barrier response to occlusion of healthy and irritated skin: Differences in trans-epidermal water loss, erythema and stratum corneum lipids. Contact Derm. 2010;63(6)313-319.

Keeling N. Patient perspectives of silicone technology in stoma care. Br J Nurs. 2015;24(5):S20, S2224

Klode J, Schöttler L, Stöffels I, Korber A, Schadendorf D, Dissemond J. Investigation of adhesion of modern wound dressings: a comparative analysis of 56 different wound dressings. J Eur Acad Dermatol Venereol. 2011;25(8):933-939

Langemo D, Hanson D, Hunter S, Thompson P, Oh IE. Incontinence and incontinence-associated dermatitis. Adv Skin Wound Care. 2011;24(3):124-140

Lei H-B, Yunjun L, Li X-M et al. Polyurethane modified by silicone: synthesis, microstructure and properties. Transaction of Beijing Institute of Technology. 2011; 31:1242-1251

Lin Y-S, Ting P-S, Hsu K-C. Does the form of dressings matter?: A comparison of the efficacy in the management of postoperative scars between silicone sheets and silicone gel: a randomized controlled trial. Medicine (Baltimore). 2018; 97(32):e11767.

https://doi.org/10.1097/MD.0000000000011767

Lyon CC. Skin disorders. In: Taylor P, ed, Stoma care in the community: a clinical resource for practitioners. Nov. 1999, London:Nursing Times Books

Machado M, Salgado TM, Hadgraft J, Lane ME. The relationship between trans-epidermal water loss and skin permeability. Int J Pharm. 2010;384(1-2):73-77

Matsui T, Amagai M. Dissecting the formation, structure and barrier function of the stratum corneum. Int Immunol. 2015;27(6):269-280

Matsumura $\mathrm{H}$, Imai R, Ahmatjan $\mathrm{N}$ et al. Removal of wound dressing and its effects on the strateum corneum of the skin: comparison of eight different adhesive wound dressings. Int Wound J.

2014;11(1):50-54 
Meuleneire F, Rücknagel H. Soft silicone dressings made easy. Wounds international. 2013. https://www.woundsinternational.com/download/resource/6106

Meaume S, Le Pillouer-Prost A, Richert B, Roseeuw D, Vadoud J. Management of scars: updated practical guidelines and use of silicones. Eur J Dermatol. 2014;24(4):435-443

Monstrey S, Middlekoop E, Vranckx J et al. Updated scar management practical guidelines: Noninvasive and invasive measures. J Plastic Reconst Aesthet Surg.. 2014;67:1017-1025

Niessen FB, Spauwen PH, Robinson PH, Fidler V, Kon M. The use of silicone occlusive sheeting (Sil$\mathrm{K}$ ) and silicone occlusive gel (Epiderm) in the prevention of hypertrophic scar formation. Plast Reconstr Surg. 1998;102(6):1962-1972

Nikkonen M, Pitkanen J, Al-Qattan M. Problems associated with the use of silicone gel sheeting for hypertrophic scars in the hot climate of Saudi Arabia. Burns : journal of the International Society for Burn Injuries. 2001; 27:498-501. https://doi.org/10.1016/S0305-4179(01)00004-3

O'Brien L, Jones D. Silicone gel sheeting for preventing and treating hypertrophic and keloid scars. Cochrane Database Syst Rev. 2013;(9):CD003826. https://doi.org/10.1002/14651858. CD003826.pub3

Omura Y, Yamabe M, Anazawa S. Peristomal skin disorders in patients with intestinal and urinary ostomies. J Wound, Ostomy Contin Nursing. 2010;37(3):289-298

Owen MJ. Silicone hydrophobicity and oleophilicity. Silicon. 2014;9(5):651-655

Patton ML, Mullins RF, Smith D, Korentager R. An open, prospective, randomised pilot investigation evaluating pain with the use of a soft silicone wound contact layer vs bridal veil and staples on split thickness skin grafts as a primary dressing. J Burn Care Res 2013;34(6):674-681

Platt AJ, Phipps A, Judkins K. A comparative study of silicone net dressing and paraffin gauze dressing in skin-grafted sites. Burns. 1996; 22(7):543-545. https://doi.org/10.1016/03054179(96)00035-6

Rabello FB, Souza CD, Farina JA. Update on hypertrophic scar treatment. Clinics. 2014;69(8):565573

Rudoni C, Dennis H. Accessories or necessities? Exploring consensus on usage of stoma accessories. Br J Nurs. 2009;18(18):1106-1112

Smith RJM, Sica J, Primett C. A study of the cost-effectiveness of flange extenders (in press). Presentation at the European Conference of Enterostomal Therapists, Salzberg, Austria, 2007

Suess-Burghart A, Zomer K, Schwanke D. A multicentre clinical evaluation of Cuticell Contact silicone wound contact layer in daily practice. Comm Wound Care. 2015;Jun(Suppl):S38-S41

Taylor NA, Machado-Moreira CA. Regional variations in trans-epidermal water loss, eccrine sweat gland density, sweat secretion rates and electrolyte composition in resting and exercising humans. Extrem Physiol Med. 2013;2(1):4

Van Onselen J. Scars: impact and management, with a focus on topical silicone-based treatments. J Aesthet Nurs 2019;8(1):27-31

Wang Z, Zhao LH, Jia ZD, Guan ZC. Water and moisture permeability of high-temperature vulcanized silicone rubber. IEEE Trans Dielect Electric Insul. 2017;24(4):2440-2448

Warner RR, Stone KJ, Boissy Y. L. Hydration disrupts human stratum corneum ultrastructure. J Invest Dermatol. 2003;120(2):275-284 
White M. Using silicone technology to maintain healthy skin in stoma care. $\mathrm{Br} \mathrm{J}$ Nurs. 2014;23(22):1190-1193

Whitehead F, Giampieri S, Graham T, Grocott P. Identifying, managing and preventing skin maceration: a rapid review of the clinical evidence. J Wound Care. 2017;26(4):159-165

Williams J, Gwillam B, Sutherland $\mathrm{N}$ et al. Evaluating skin care problems in people with stomas. $\mathrm{Br} \mathrm{J}$ Nurs. 2010; 19(Sup7):S6-S15. https://doi.org/10.12968/bjon.2010.19.Sup7.78569

Woo KY, Beeckman D, Chakravarthy D. Management of moisture-associated skin damage: a scoping review. Adv Skin Wound Care. 2017;30(11):494-501

Zhao J, Luo G, Wu J, Xia H. Preparation of microporous silicone rubber membrane with tunable pore size via solvent evaporation-induced phase separation. ACS Appl Mater Interfaces. 2013;5(6):2040-2046

Zielecka M, Bujnowska E (2006). Silicone-containing polymer matrices as protective coatings. Prog Organ Coat. 2006;55(2),160-167 


\section{Figures}

Figure 1. Complications caused by effluent contact with peristomal skin

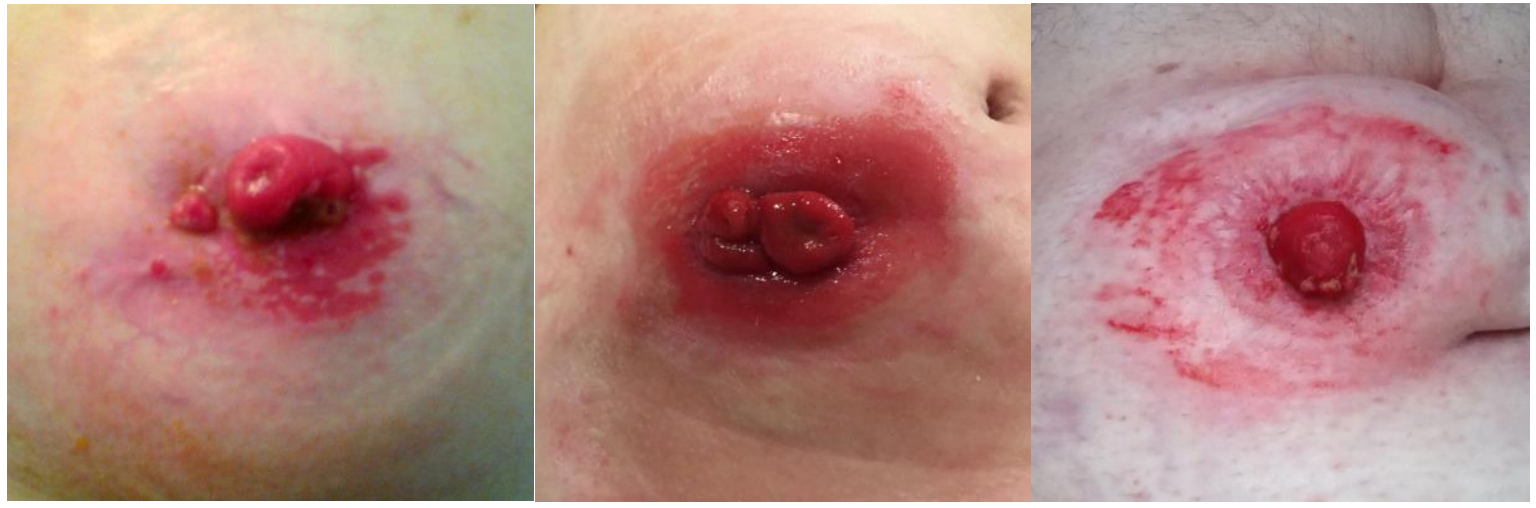

Figure 2. Silicone-based barrier film (Trio Elisse)

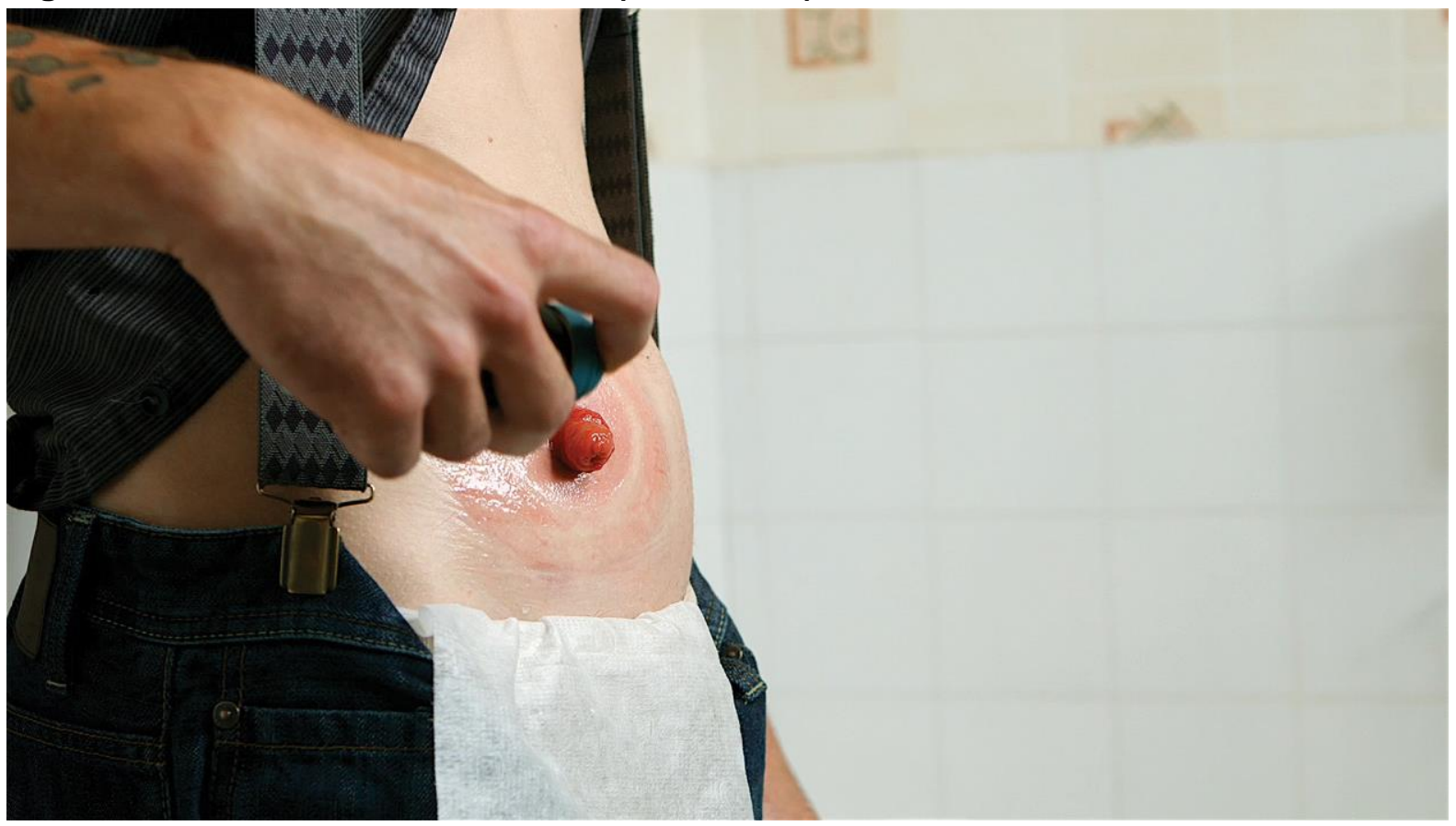


Figure 3. Silicone-based adhesive remover (Trio Elite)

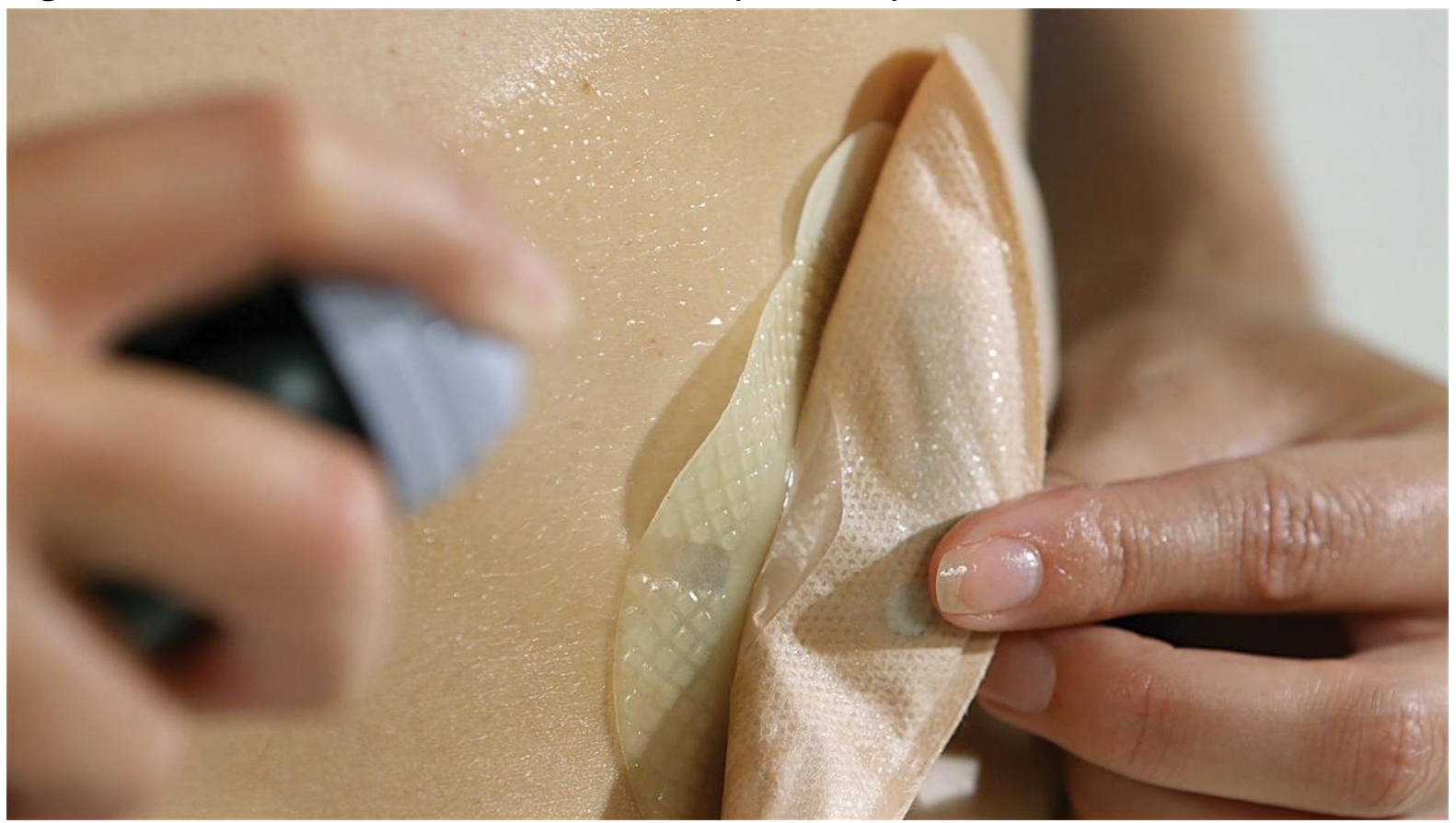

Figure 4. Silicone-based filler gel (Trio Silken)

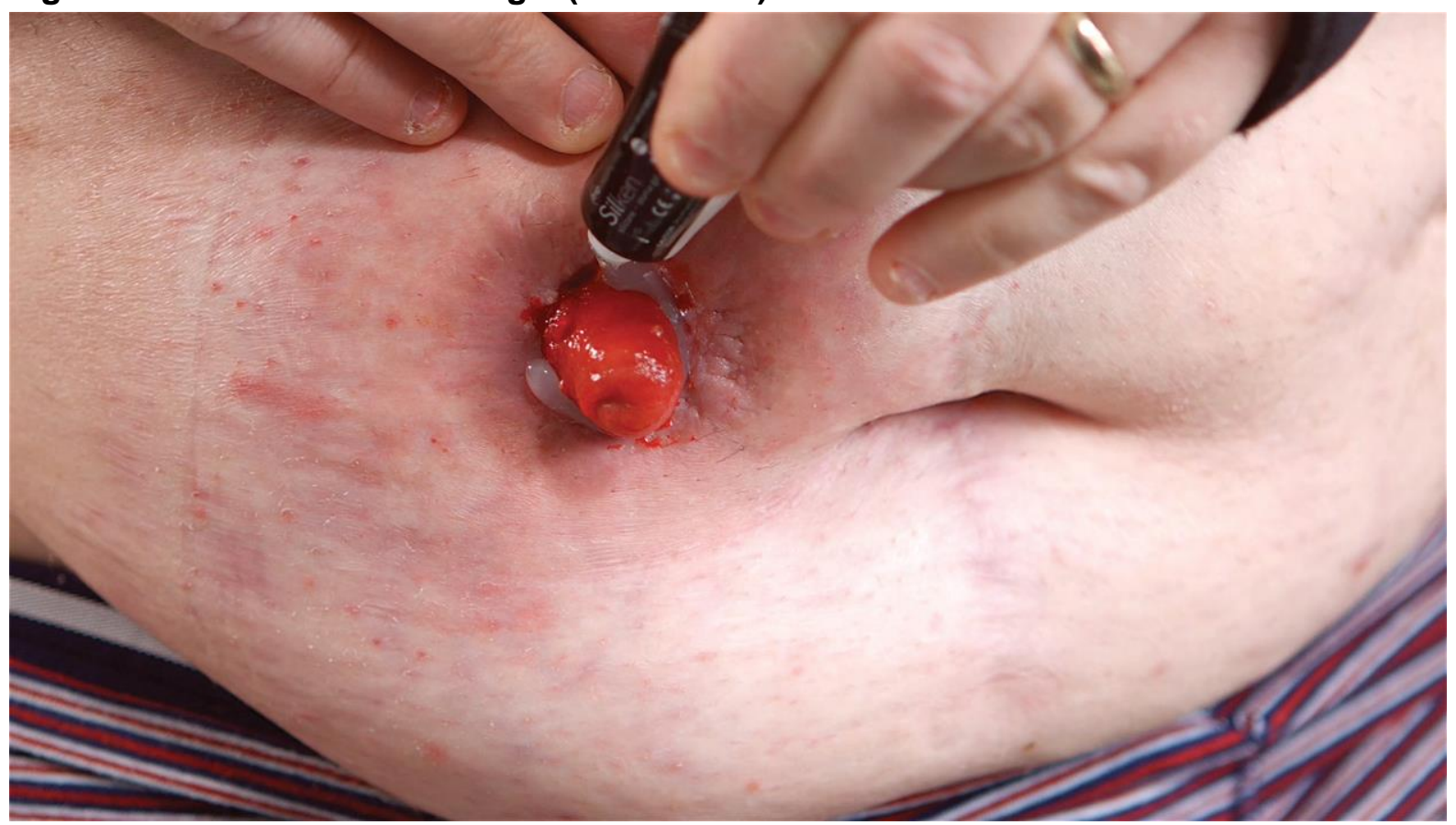


Figure 5. Structure of the skin

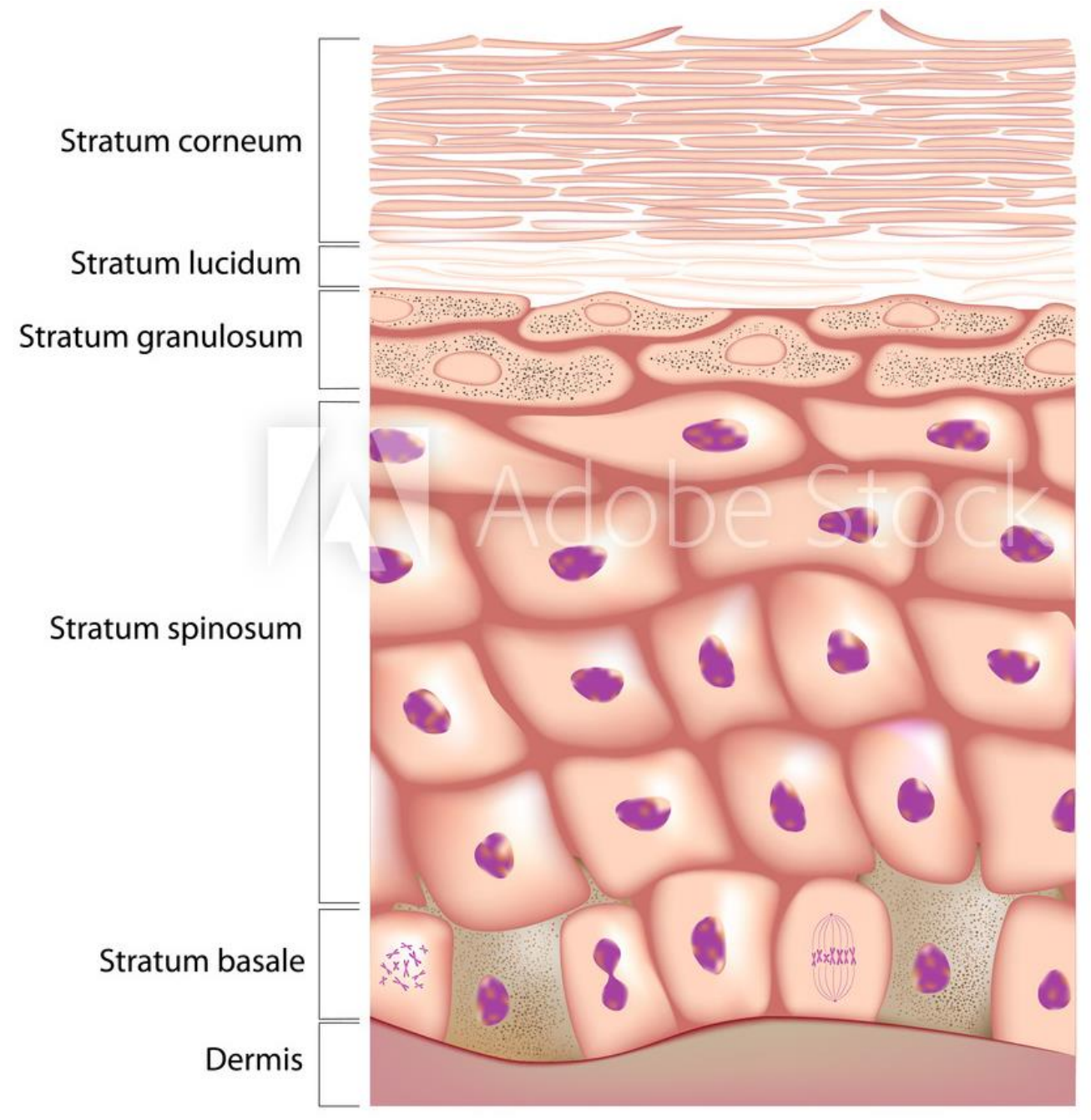


Figure 6. Proposed moisture management technique of silicone vs hydrocolloid flange extenders on occluded skin

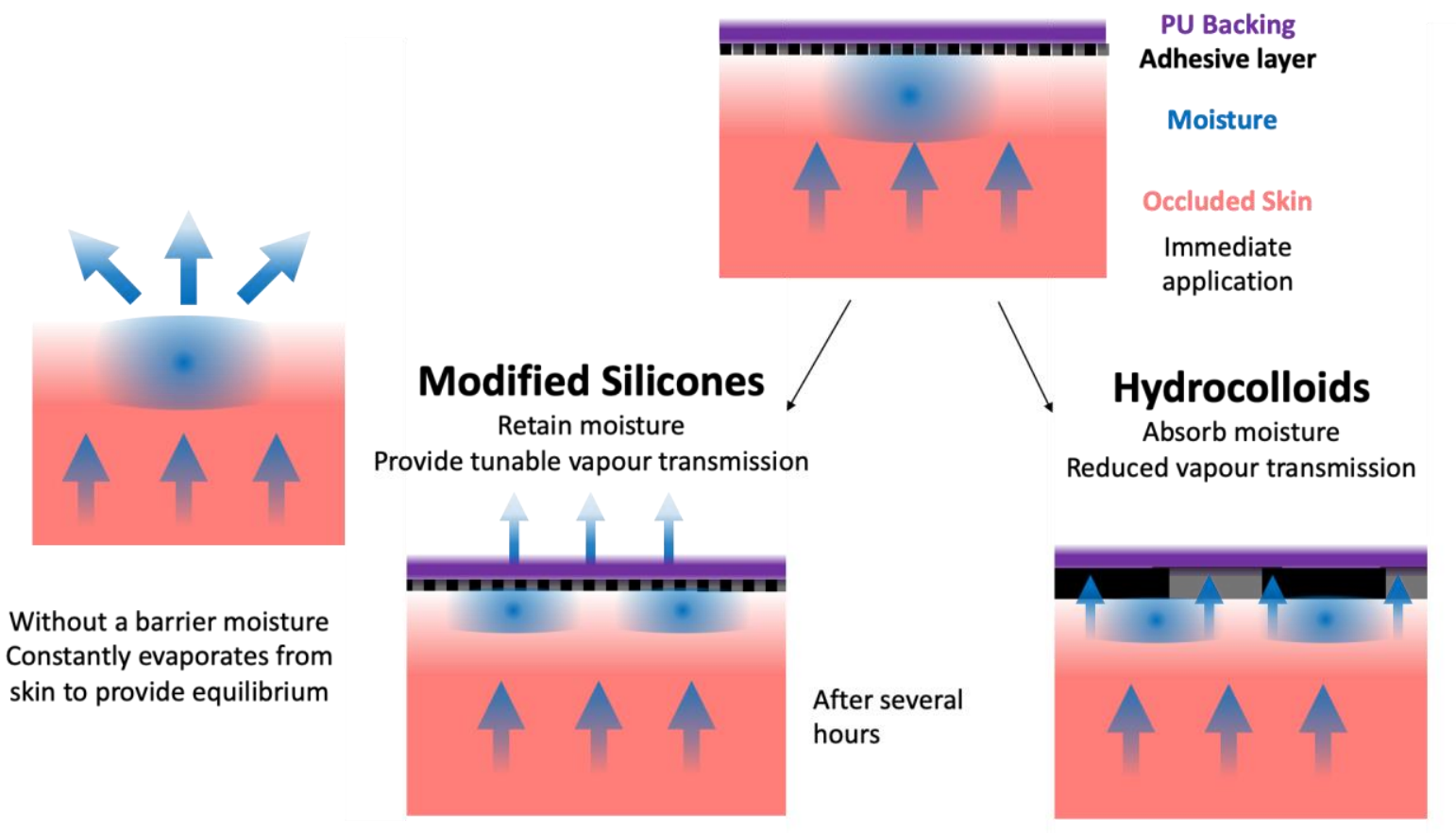

Figure 7. Breakdown of hydrocolloid flange due to saturation

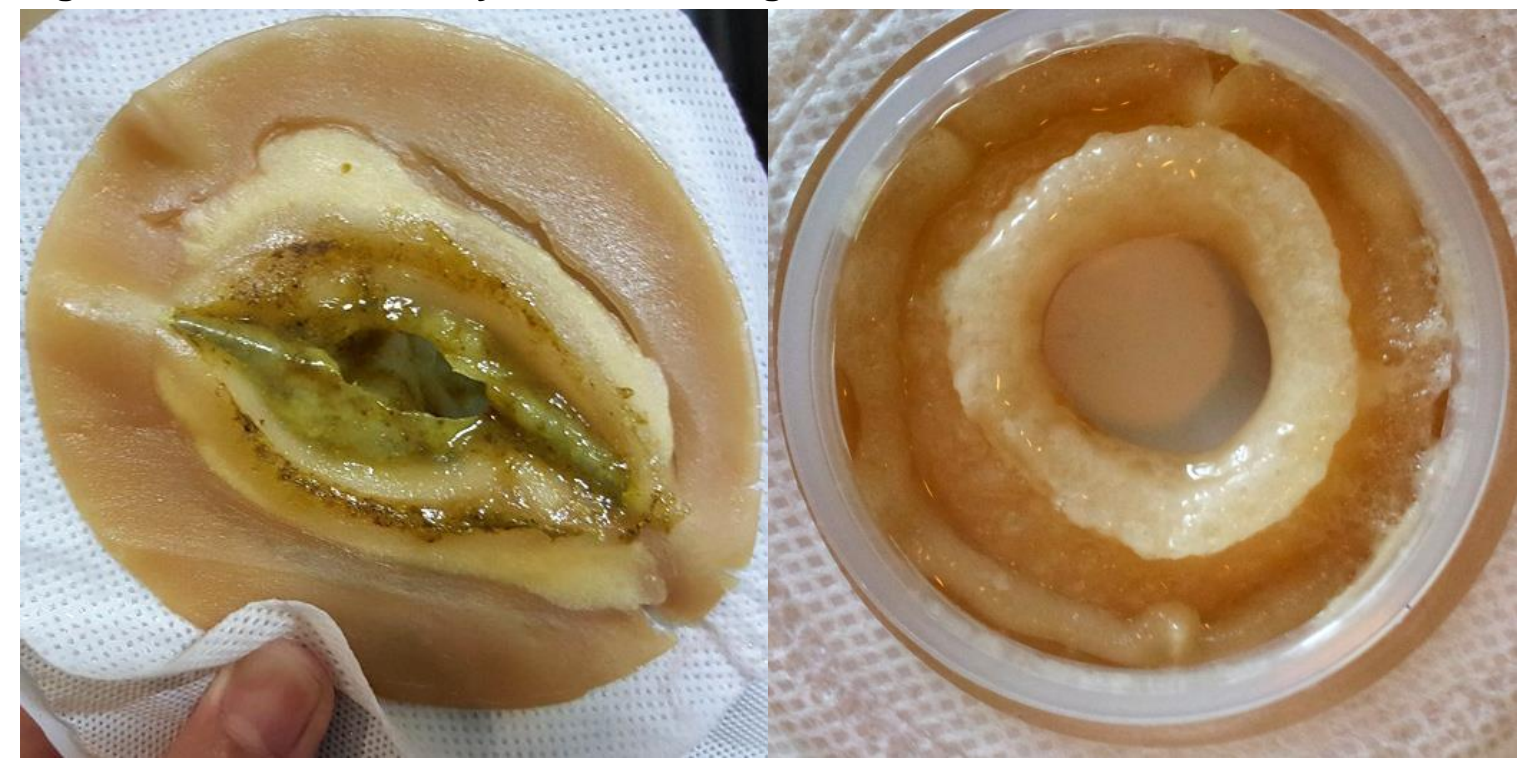


Figure 8. Peel force on peristomal skin during removal of an adhesive flange

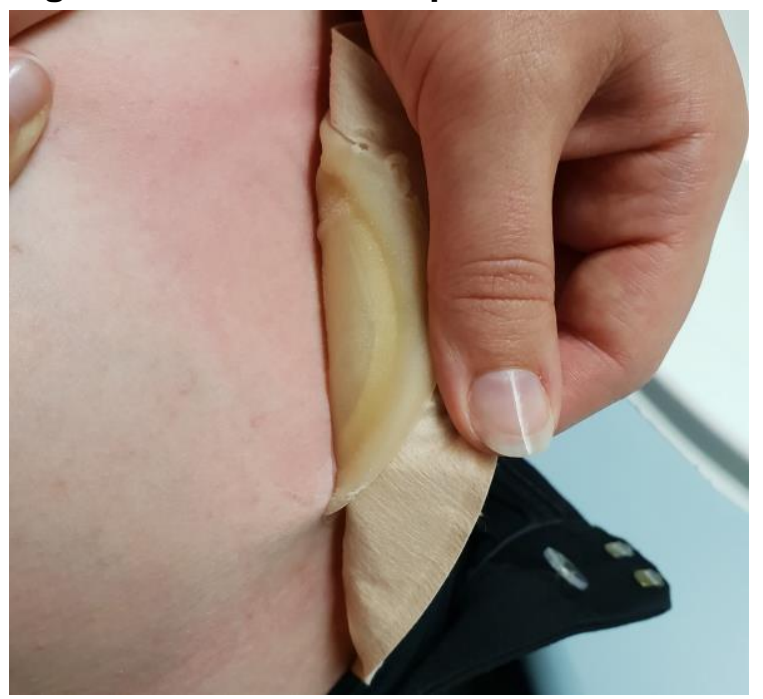

Figure 9. Gradual diffusion of water molecules through a novel silicone compound

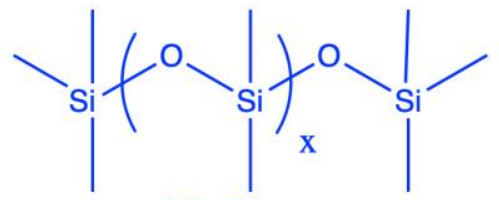

Oily Phase

Silicone Polymer Backbone

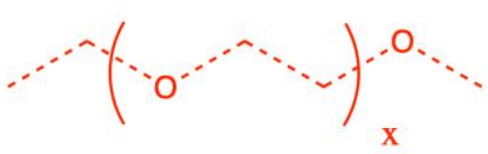

Aqeous Phase Hydrophilic Polymer Additive

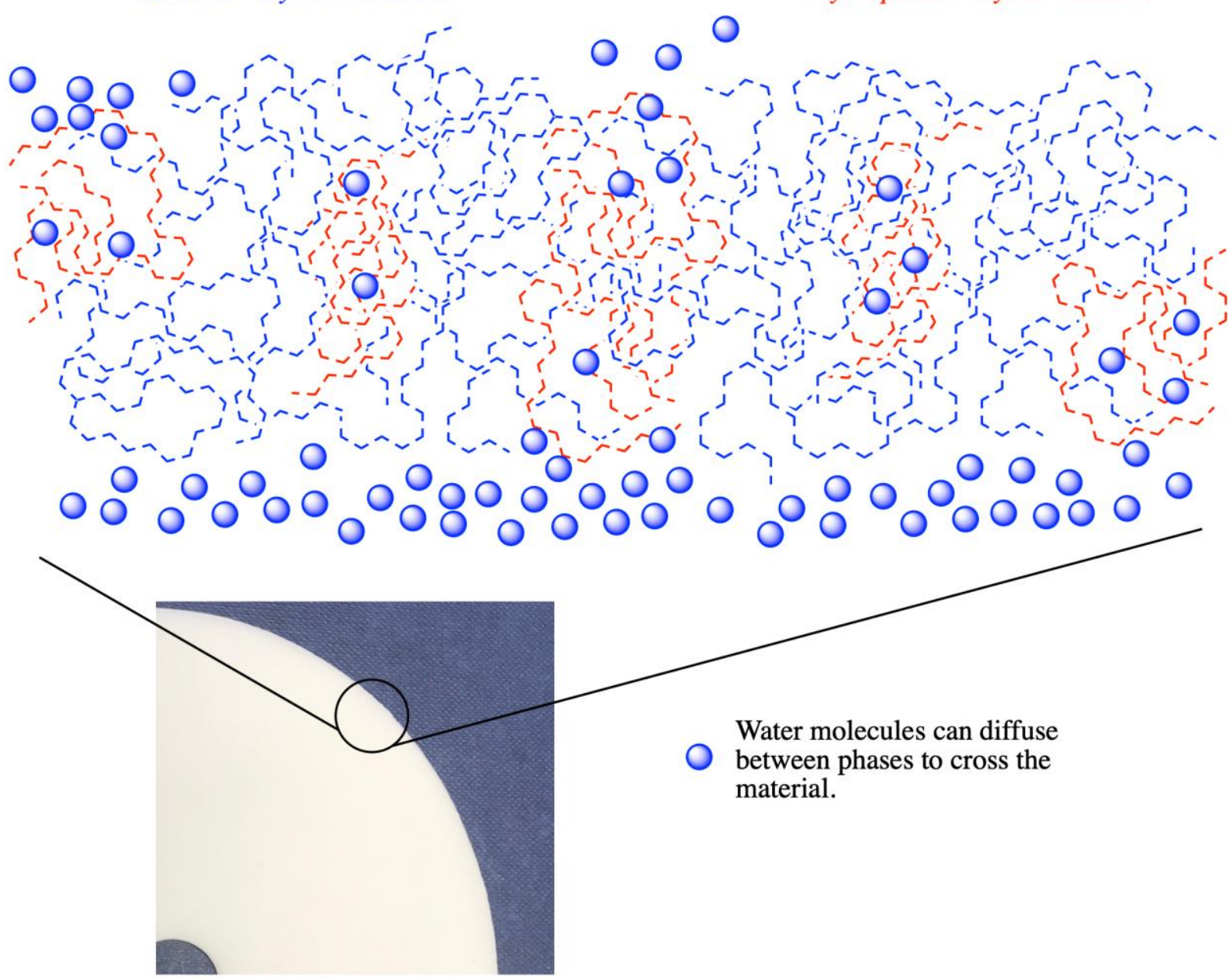


Figure 10. Peel test on porcine skin comparing degree of skin tearing in silicone (a) and hydrocolloid (b) protype flanges

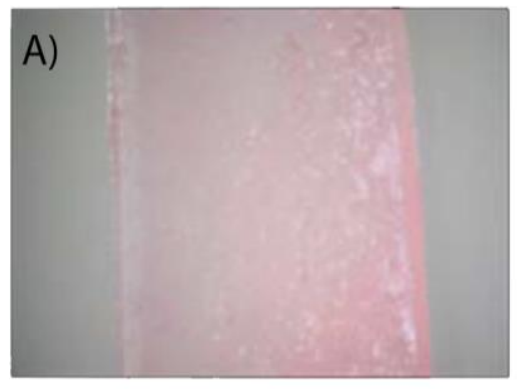

B)
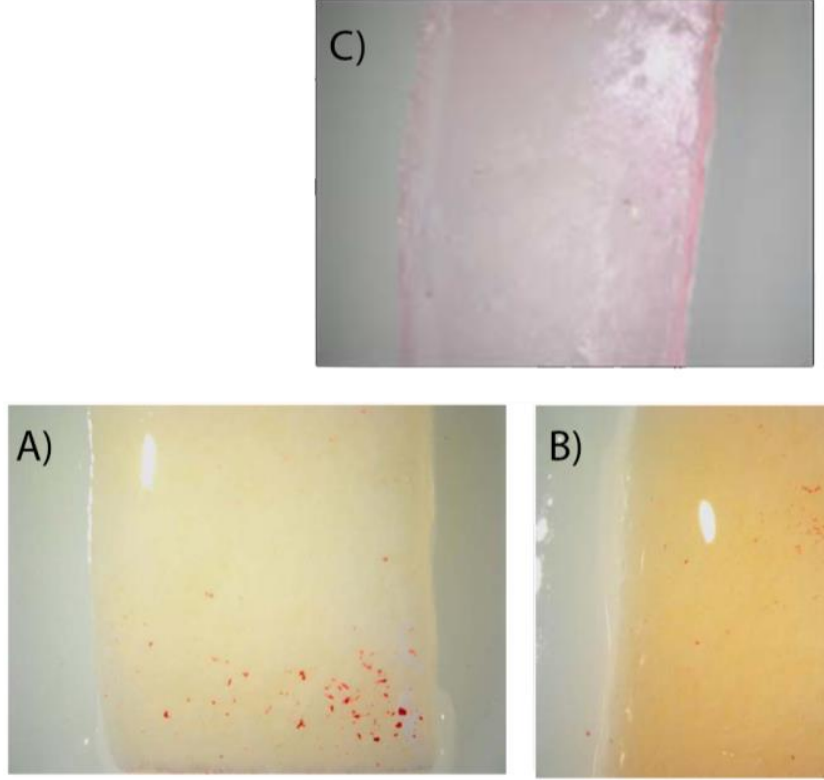

B)

C)
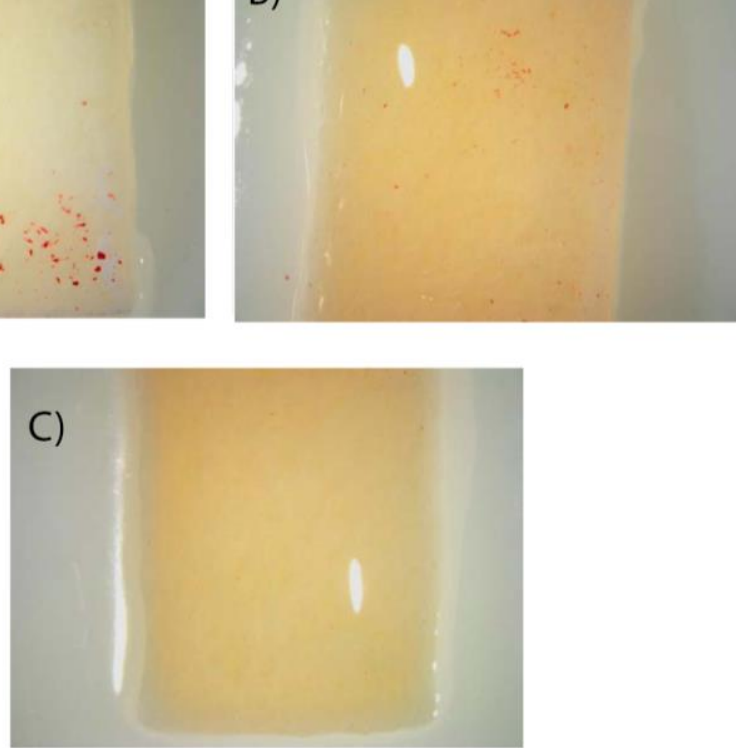
Figure 11. Silicone-based flange extender (Trio Silex)

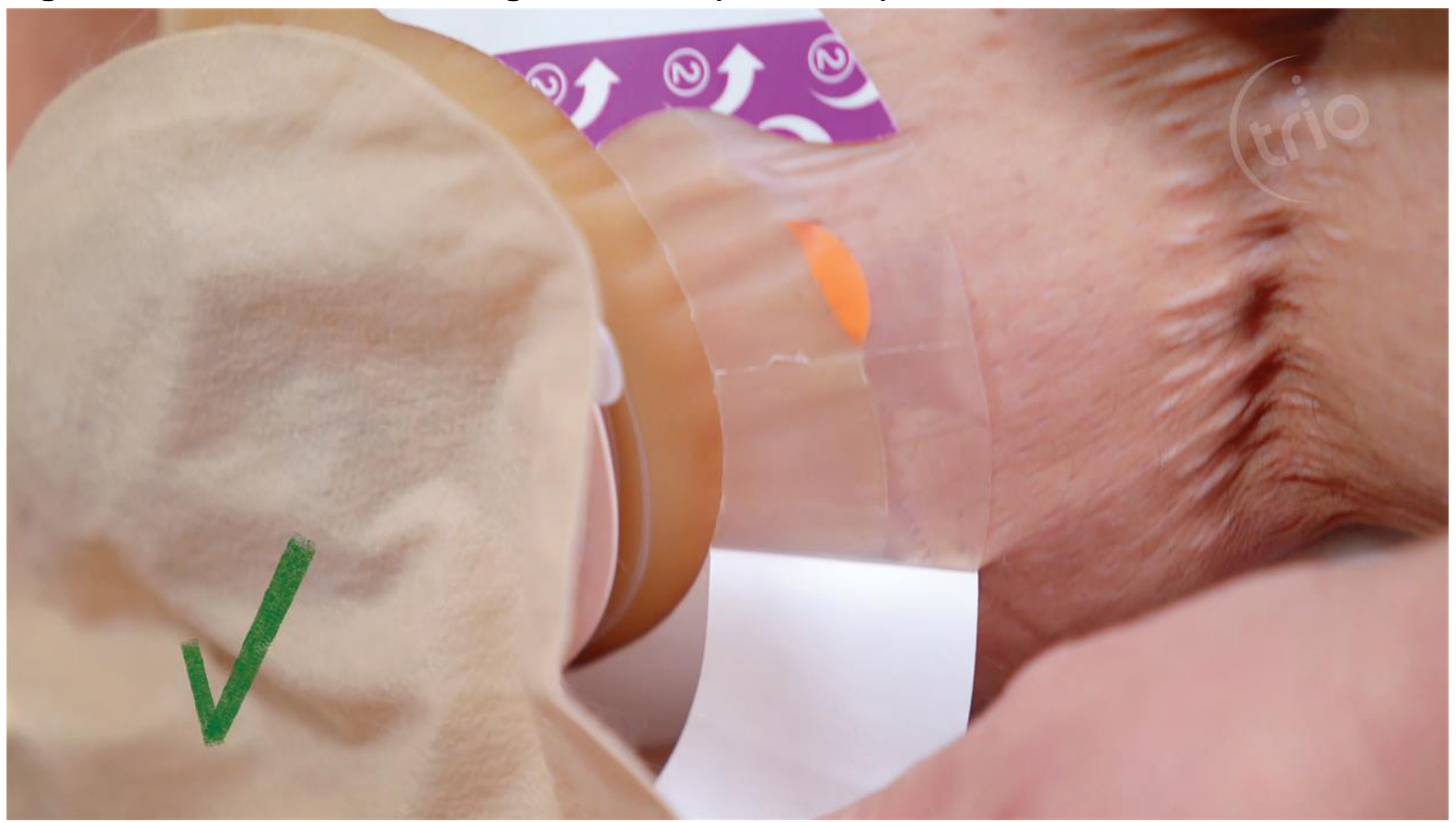

Figure 12. Silicone-based seal (Trio Siltac)

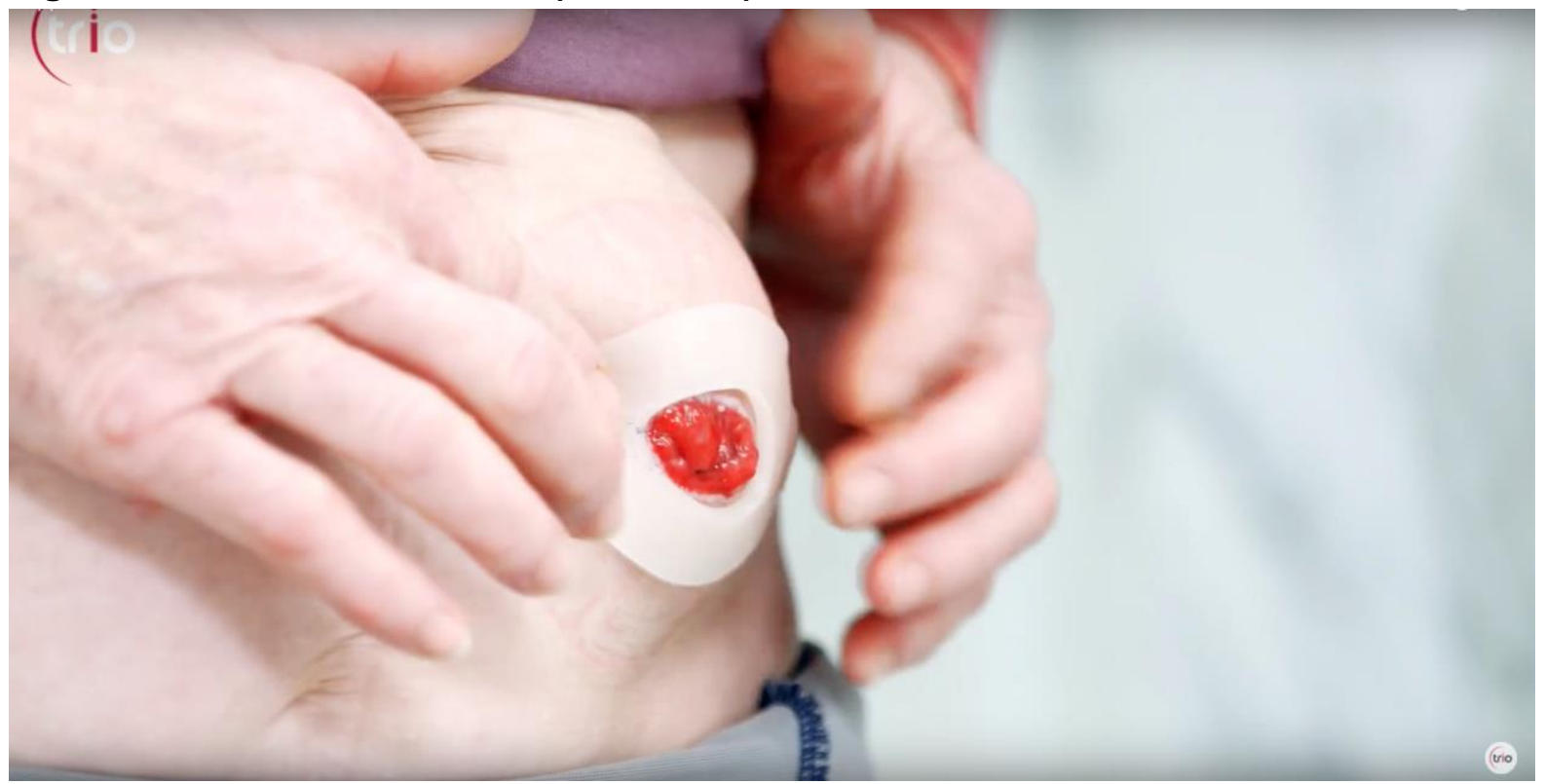


Figure 13. Prototype silicone flange for a stoma appliance

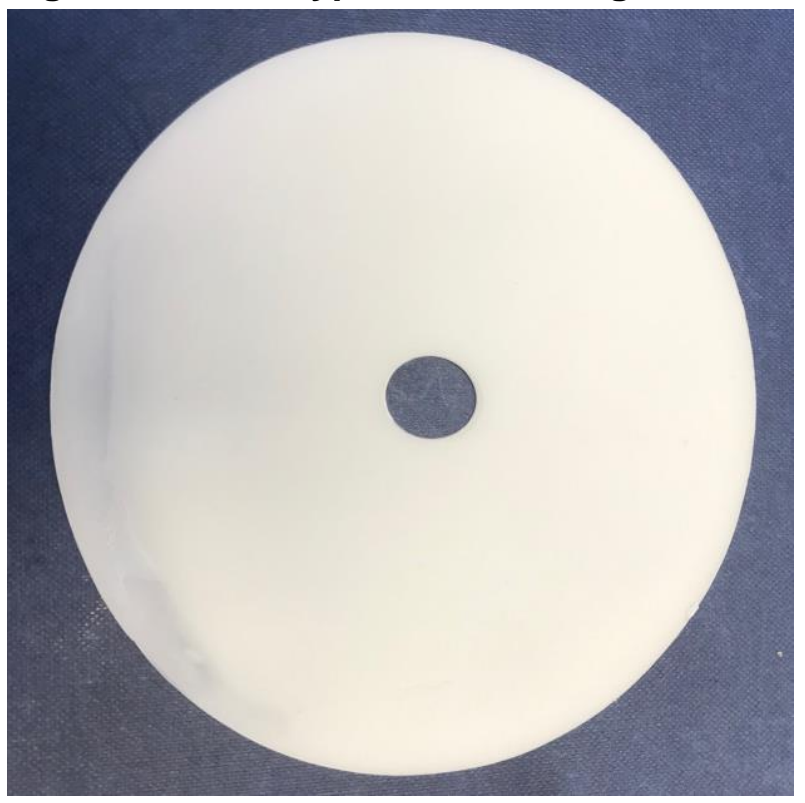

